\title{
Trajetos e escolhas de Jean-Claude Schmitt
}

\section{The trajectories and choices of Jean-Claude Schmitt}

Entrevista com

Jean-Claude Schmitt

i Professor emérito, École des

Hautes Études en Sciences Sociales. Paris - França

jean-claude.schmitt@ehess.fr

\section{Concedida a}

\section{Leandro Alves Teodoro ${ }^{i i}$}

ii Pós-doutorando, Departamento de História/Universidade Estadual de Campinas.

Campinas - SP - Brasil

orcid.org/0000-0002-5580-8838

leandroateodoro@uol.com.br
TEODORO, Leandro Alves. Trajetos e escolhas de Jean-Claude Schmitt. História, Ciências, Saúde - Manguinhos, Rio de Janeiro, v.26, n.2, abr.-jun. 2019, p.643-648.

\section{Resumo}

Nesta entrevista, um dos mais renomados medievalistas franceses da atualidade, Jean-Claude Schmitt, responde a diferentes questões concernentes não apenas às suas escolhas teórico-metodológicas, mas também aos temas de seus últimos trabalhos. Conhecido como um dos principais herdeiros da história antropológica de Jacques Le Goff, Schmitt faz um balanço de uma trajetória que resultou em trabalhos diversos, desde edições de documentos até obras sobre as imagens medievais, sem nunca perder de vista o compromisso de interrogar as crenças dos homens e as permanências do imaginário da Idade Média na cultura ocidental. Palavras-chave: Jean-Claude Schmitt (1946- ); entrevista; historiografia.

\section{Abstract}

In this interview, one of today's best-known French medievalists, Jean-Claude Schmitt, responds to various questions about his theoretical and methodological choices as well as the themes of his recent work. Schmitt is known as one of the main heirs of the anthropological history of Jacques Le Goff, and sums up his trajectory which resulted in a variety of work ranging from editing documents to work on medieval images, without ever losing sight of his commitment to questioning the beliefs of men and sojourns into the imagery of the Middle Ages in western culture.

Keywords: Jean-Claude Schmitt (1946- ); interview; historiography. 
A presentamos aqui uma entrevista ${ }^{1}$ com um dos mais celebrados medievalistas da atualidade, o historiador francês Jean-Claude Schmitt, nascido em 1946. Conhecido como um dos principais seguidores da história antropológica de Jacques Le Goff, grande nome da terceira geração da Escola dos Annales, o entrevistado é autor de várias obras que o consagraram como referência na área da história da Idade Média. Schmitt possui uma produção vasta que se destaca por trabalhos tanto mais específicos e com assuntos bastante recortados - Le saint lévrier: Guinefort, guérisseur d'enfants depuis le XIII siècle (Schmitt, 1979) e La conversion d'Hermann le Juif : autobiographie, histoire et fiction (Schmitt, 2014a) - quanto por obras mais gerais, em que explora diferentes aspectos das crenças dos homens e mulheres do medievo - Le corps, les rites, les rêves, le temps: essais d'anthropologie médiévale (Schmitt, 2001, 2014b); Les revenants: les vivants et les morts dans la société médiévale (Schmitt, 1994, 1999); Le corps des images (Schmitt, 2002, 2007); La raison des gestes dans l'Occident Médiéval (Schmitt, 1990), Les rythmes au Moyen Âge (2016) - e muitos outros. ${ }^{2}$ Esse historiador também investiu na direção de livros coletivos, especialmente do Dictionnaire raisonné de l'Occident medieval (Schmitt, Le Goff, 1999, 2002), coordenado junto com o historiador Jacques Le Goff.

Esses e outros estudos de Jean-Claude Schmitt influenciaram o trabalho de diferentes historiadores, inclusive do Brasil, e abriram novas veredas para outros pesquisadores explorarem desde as crenças medievais até a maneira como a Idade Média ajudou a criar os andaimes culturais e morais da Época Moderna. De olho nas impressões dos medievos acerca de suas práticas devocionais e supersticiosas, esse historiador não perdeu de vista as longas estruturas que, segundo ele, foram se solidificando da Alta Idade Média ao limiar da Modernidade.

Ao longo desta entrevista, Jean-Claude Schmitt comenta um pouco o caminho que percorreu e seus trabalhos sobre textos e imagens do período medieval, demarcando certas inspirações e metas de uma trajetória de mais de 30 anos como diretor de estudos. Comenta, igualmente, desde seus últimos trabalhos até a formação dos historiadores na França dos dias de hoje e o financiamento público realizado para a manutenção de novas pesquisas científicas nesse país.

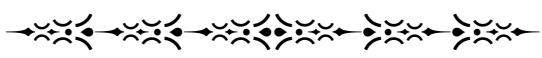

$\mathrm{Na}$ sua vasta obra, encontramos alguns pontos recorrentes que dizem respeito à formação do Ocidente. Olhando retrospectivamente, alguma questão sobressai em detrimento de outras? Ou em cada nova pesquisa o senhor busca trabalhar a partir de um ponto de vista diferente?

$\mathrm{Na}$ verdade, eu procuro, para cada estudo importante, para cada novo livro, iniciar uma nova pesquisa visando evitar a repetição e o tédio - em mim primeiro e no leitor em seguida. Outros historiadores procedem de forma diferente e preferem aprofundar o mesmo campo ao longo de sua carreira. Sem dúvida, eles se renovam também, mas de outra forma, menos visível. De minha parte, é fácil ver que ainda há um grande parentesco entre meus livros, tanto na orientação temática quanto no método. 
Quais as motivações que o estimularam a analisar, durante sua trajetória intelectual, tanto imagens quanto obras escritas?

Meu interesse em imagens é muito antigo. Isso remonta à minha infância, ao ambiente familiar em que fui criado, perto de obras de arte e, em especial, de pinturas antigas. Eu sempre amei desenhar e pintar. Durante as minhas pesquisas como historiador, pareceu-me evidente que o documento visual tinha o seu papel, dando informações complementares e diferentes dos textos e da arqueologia. Então, eu queria levar isso em conta, mas não como um historiador da arte, cuja especialidade é isto, mas como um historiador que coloca as imagens no contexto histórico, cultural e social, isto é, num plano mais vasto. Assim, eu fui ensinado que a imagem não era simplesmente a imagem material, mas também o imaginário, do qual os textos falam também à sua maneira: os fantasmas, os sonhos etc. Eu coloquei, portanto, a imagem nos sentidos mais gerais - que eu nomeio "imago" - no centro de minha atenção, no cruzamento de textos e imagens materiais e no coração da cultura medieval.

Que papel o senhor atribui às suas edições de documentos durante sua trajetória acadêmica? Novos caminhos puderam ser tomados a partir da publicação de uma fonte?

Confesso que não fiz muitas edições críticas de documentos originais, embora essa atividade acadêmica seja essencial para a renovação da documentação. Mas colaborei com meus colegas do Gahom (Groupe d'Anthropologie Historique de l'Occident Médiéval) ${ }^{3}$ na edição crítica das coleções de exempla. Da minha parte, dediquei-me a traduzir textos latinos em francês, com Pierre Monnet, a Vita de Charles IV de Bohemia (Monet, Schmitt, 2010), ou com Gisèle Besson, a antologia de sonhos autobiográficos na Idade Média (Besson, Schmitt, 2017). Essas traduções são importantes não apenas para estudiosos, mas também para leitores não especializados. Certamente, a publicação de uma fonte desconhecida ou mal conhecida pode estimular novas pesquisas: eu mesmo tive essa experiência ao publicar um livro a partir da relação autobiográfica da conversão do antigo judeu Hermann, um texto que tinha sido objeto de uma nova edição crítica da Monumenta Germaniae Historica (MGH) alguns anos antes, o que deu origem a acalorados debates.

Haveria diferenças, na França, entre uma edição realizada por um historiador e outra elaborada por um profissional de outro campo de estudos, como um filólogo?

O saber filológico é essencial para realizar uma edição crítica. Mas ele não é suficiente: é necessário apresentar o texto editado em seu contexto histórico, de modo que a compreensão de algumas palavras ou expressões, ou mesmo a intenção do documento, requer o saber complementar do historiador acerca da economia, da política, da sociedade, da cultura. Um trabalho como esse é, portanto, necessariamente um trabalho de equipe.

Em seu último livro, Les rythmes au Moyen Âge (Schmitt, 2016), o senhor afirma que, embora questione os documentos a partir de inquietações do tempo presente, suas respostas não podem ser dadas fora dos limites da própria Idade Média. Quais seriam então os principais desafios para 
que uma história da longa Idade Média - cujo alvo são categorias que perduraram durante séculos - não corra o risco de fornecer respostas transtemporais?

A "longa duração" não significa o "tempo imóvel" e o risco de atemporalidade. A história é movimento permanente, mudança contínua, mas muitas vezes em pequenos toques sucessivos, que não afetam necessariamente toda a espessura da sociedade ao mesmo tempo. Na obra Les rythmes au Moyen Âge, eu falo do "mosaico" do tempo histórico na longa duração. É, sem nenhuma dúvida, esse o motivo pelo qual Jacques Le Goff falava de "longa Idade Média", que não cessava de evoluir entre o século V e o XVIII. Os limites desse longo período são justificados pelos dois principais fenômenos que o enquadram: de um lado, a cristianização do Império Romano; de outro, a Revolução Industrial. A partir disso, pode-se recortar um tempo menor de acordo com o objeto específico que estamos estudando (por exemplo, levando em consideração grandes eventos, tais como a Reforma Protestante, a descoberta da imprensa ou a do Novo Mundo etc.). Pode-se também alongar a observação acerca da "Idade Média", na qual nós ainda vivemos em determinados aspectos, como no que diz respeito à importância do ritmo semanal, que eu mostrei, iniciado pelo Gênese, e que rege sempre nossas semanas e a alternância do trabalho e do lazer.

Como o senhor definiria o lugar do historiador na sociedade francesa? Espera-se do historiador uma formação intelectual?

O lugar da história na França como disciplina científica e literária e do historiador como especialista nessa disciplina é sem dúvida singular, em comparação com outros países europeus ou com os Estados Unidos, para citar apenas alguns. Ele é proveniente da importância que a reflexão histórica adquiriu no século XIX, porquanto era necessário justificar a nova ordem social oriunda da Revolução: inscrevê-la em uma continuidade cultural e política e, ao mesmo tempo, explicar a ruptura. Esse esforço historiográfico parcialmente partilhado no exterior (penso na $\mathrm{MGH}$, pela mesma época, mas com um propósito diferente) - começa com a Restauração, mas recebe, acima de tudo, um grande impulso no âmbito escolar sob a Terceira República (depois de 1871). A história é rapidamente associada à geografia (da França em primeiro lugar), instalando-se no coração dos programas escolares, não apenas como conhecimento, mas como formação de cidadãos. Trata-se certamente de uma história acontecimental, política e nacional. Então as coisas mudaram, especialmente entre as duas guerras mundiais, dada a refundação da ciência histórica pelos Annales, Marc Bloch, Lucien Febvre, em torno de um projeto também inspirado em considerações políticas, no nobre sentido do termo. A história não perdeu sua função de formação do "honesto homem" cultivado e do cidadão. Até recentemente, e ainda hoje, para um político, está vivo o costume de incluir na sua bibliografia um livro de história, se possível, a biografia histórica de um grande homem ou até mesmo de um rei prestigiado do Antigo Regime (François I, Henri IV, para citar apenas exemplos recentes). A referência à história é quase permanente nos debates públicos, bem mais do que em outros países, eu creio. Veja também o sucesso de grandes séries como Lieux de mémoire, de Pierre Nora (1997): elas eram possíveis apenas na França e foram às vezes imitadas em outros lugares. 
Como o senhor avalia o financiamento público que é realizado, na França, para a formação de base de um professor ou de um pesquisador?

O financiamento público da formação e, depois, da carreira dos historiadores (como de outros universitários) é exclusivo da França em relação a qualquer outro lugar, contrariando o que acontece na Grã-Bretanha ou nos Estados Unidos (ensino pago e caro, universidades privadas). O Estado consente, assim, um considerável compromisso financeiro, que pesa sobre os contribuintes. Esse financiamento tem limites e varia de acordo com as disciplinas (a física nuclear é muito mais onerosa do que a história!). Que os meios parecem sempre insuficientes é evidente. É provável também que o dinheiro disponível pudesse ser, talvez, mais bem empregado, com menos estruturas administrativas sobrepostas e inutilmente complexas e mais bolsas para estudantes. Eu noto, no entanto, o grande esforço realizado nos últimos anos nas bibliotecas universitárias (vejam as da Sorbonne, do INHA - Institut National d'Histoire de l'Art etc.) e para a renovação dos campi universitários (por exemplo, em Toulouse, Dijon, Orléans, que eu tenho visitado nos últimos meses). Eu me ocupo em parte da criação ex nihilo do grande campus Condorcet para a pesquisa em ciências humanas e sociais em Aubervilliers. Em 2019, ele acolherá 15 mil estudantes de mestrado, doutorado, pós-doutorado, pesquisadores e professores ao redor de uma grande biblioteca digitalizada e convencional (um milhão de volumes disponibilizados gratuitamente); isso custará muito dinheiro proporcionado pelo Estado, pela administração regional, pelas coletividades territoriais. ${ }^{4}$

\section{O senhor poderia comentar um pouco os seus projetos em andamento?}

Acabei de publicar dois livros, e preciso respirar um pouco! Estou pensando em uma nova coleção de artigos, mas preciso de tempo para escolhê-los entre vários títulos e comentálos. Essa será uma oportunidade para refletir uma vez mais sobre o procedimento da antropologia histórica, que melhor caracteriza minha abordagem como historiador no cruzamento tanto de disciplinas quanto da história cultural com a história social. Também publicarei em pouco tempo um pequeno livro, intitulado Penser par figures, acerca do uso de diagramas, ilustrações, gráficos, meios mnemotécnicos e ferramentas pedagógicas. Essa é uma questão que me intriga há muito tempo. Além disso, eu gostaria especialmente de ajudar jovens pesquisadores a conduzir suas pesquisas; muitos me pedem prefácios para suas teses que serão publicadas ou para um primeiro livro, o que eu faço com prazer na intenção de ajudá-los e também para que eu fique atualizado acerca das novas tendências historiográficas, pois a história não cessa de se renovar.

\section{AGRADECIMENTOS}

Entrevista realizada no âmbito do grupo "O ensino da fé cristã na Península Ibérica (sécs. XIV e XV)", financiado pelo auxílio Jovem Pesquisador da Fapesp (Processo 2017/11111-9) e sediado na Unicamp. Para mais informações, ver: <http://umahistoriadapeninsula.com/>. O autor também é membro do grupo temático "Escritos sobre os novos mundos", sediado na Unesp, campus Franca, instituição na qual é professor do Programa de Pós-graduação em História. 


\section{NOTAS}

${ }^{1}$ Entrevista traduzida do francês para o português pelo autor.

${ }^{2}$ Outras obras do autor publicadas em português são Levi, Schmitt (1996), Schmitt (1997) e Le Goff, Schmitt (2002). Para informações mais precisas acerca da trajetória de Jean-Claude Schmitt, consultar: <http:// crh.ehess.fr/index.php?246>.

${ }^{3}$ O Gahom foi fundado por Jacques Le Goff em 1978, junto ao Centre de Recherches Historiques, laboratório da École de Hautes Études en Sciences Sociales (Ehess).

${ }^{4}$ Ver <https://www.campus-condorcet.fr/>.

\section{REFERÊNCIAS}

BESSON, Gisèle; SCHMITT, Jean-Claude. Rêver de soi: les songes autobiographiques au Moyen Âge. Toulouse: Anacharsis. 2017.

LE GOFF, Jacques; SCHMITT, Jean-Claude. Dicionário temático do Ocidente medieval. São Paulo: Edusc. 2002.

LEVI, Giovanni; SCHMITT, Jean-Claude (Org.). História dos jovens. 2v. São Paulo: Companhia das Letras. 1996.

MONNET, Pierre; SCHMITT, Jean-Claude. Vie de Charles IV de Luxembourg. Paris: Les Belles Lettres. 2010.

NORA, Pierre.

Les lieux de mémoire. 3v. Paris: Gallimard. 1997.

SCHMITT, Jean-Claude.

Les rythmes au Moyen Age. Paris: Gallimard. 2016.

SCHMITT, Jean-Claude.

La conversion d'Hermann le Juif: autobiographie, histoire et fiction. Paris: Seuil. 2014a.

SCHMITT, Jean-Claude.

O corpo, os ritos, os sonhos, o tempo: ensaios de antropologia medieval. Petrópolis: Vozes. 2014b.

SCHMITT, Jean-Claude.

O corpo das imagens: ensaios sobre a cultura visual na Idade Média. Bauru: Edusc. 2007.

SCHMITT, Jean-Claude.

Le corps des images: essais sur la culture visuelle au Moyen Âge. Paris: Gallimard. 2002.
SCHMITT, Jean-Claude.

Le corps, les rites, les rêves, le temps: essais d'anthropologie médiévale. Paris: Gallimard. 2001.

SCHMITT, Jean-Claude.

Os vivos e os mortos na sociedade medieval. São Paulo: Companhia das Letras. 1999.

SCHMITT, Jean-Claude.

História das superstições. Lisboa: Europa-América. 1997.

SCHMITT, Jean-Claude.

Les revenants: les vivants et les morts dans la société médiévale. Paris: Gallimard. 1994.

SCHMITT, Jean-Claude.

La raison des gestes dans l'Occident Médiéval. Paris: Gallimard. 1990.

SCHMITT, Jean-Claude.

Le saint lévrier: Guinefort, guérisseur d'enfants depuis le XIII siècle. Paris: Flammarion. 1979.

SCHMITT, Jean-Claude; LE GOFF, Jacques. Dicionário analítico do Ocidente medieval. Coordenador da tradução Hilário Franco Júnior. 2v. Bauru: Edusc; São Paulo: Imprensa Oficial. 2002.

SCHMITT, Jean-Claude; LE GOFF, Jacques. Dictionnaire raisonné de l'Occident médiéval. Paris: Fayard. 1999. 